\title{
RESPONSABILIDAD DEL JUEZ EN EL EJERCICIO DE SU DEBER: TEXTOS ROMANOS Y VISIGODOS
}

\author{
Olga Marlasca Martínez
}

\section{Introducción ${ }^{1}$}

La función de administrar justicia es obra humana y, como tal, sujeta a las imperfecciones de la naturaleza humana. No sólo porque aún con sano propósito se emita un fallo injusto, sino también porque el juzgador y las demás personas que intervengan en el proceso se dejen vender con dádivas e influencias que fuerzan el recto camino de la justicia ${ }^{2}$. Ciertamente las legislaciones de todas las épocas regulan la responsabilidad del juez, y nuestro punto de partida va a estar precisamente en el mundo romano. En esta etapa histórica, ya en el texto legal de las XII Tablas se procuró poner remedio a estas imperfecciones en los términos a los que nos vamos a referir en las páginas siguientes.

El presente artículo tiene por objeto mostrar la regulación jurídica de la responsabilidad del juez en el ejercicio de sus funciones como juzgador y concretamente van a ser objeto de nuestra atención, en primer lugar, determinadas disposiciones del Derecho romano contenidas en el Digesto de Justiniano, así como en el Código del citado emperador; asimismo, las Pauli Sententiae ${ }^{3}$ contienen preceptos acerca de la responsabilidad de los jueces. Por otra parte, en el contexto histórico del derecho visigodo, determinados textos legales muestran igualmente

1 Nos centramos exclusivamente en la responsabilidad del juez, no abordamos en las presentes líneas la responsabilidad de sus oficiales y asesores y de los abogados y procuradores.

2 Vid. Alvarez SuÁrez, U., Curso de Derecho Romano, tomo I. Introducción. Cuestiones preliminares. Derecho procesal civil romano (Madrid, 1955), 610.

${ }^{3}$ Edición FIRA 2: Fontes iuris romani anteiustiniani, Pars altera Auctores, eds. I. BAVIERA-I. FURLANI (Florentiae, 1940-1968). 
algunos testimonios relativos a la actuación dolosa del juez y la sanción que procedía en estos casos. Entre otros textos, nos vamos a referir en el mencionado apartado a la Lex Visigothorum ${ }^{4}$ : determinadas disposiciones de la misma contenidas en el libro 2, bajo la rúbrica: $D e$ negotiis causarum, así como otras que se encuentran en sedes distintas de la citada ley, tienen relación con el tema objeto de estudio en las siguientes líneas. Al final de cada disposición de la lex mencionada se incluye la versión de la misma recogida en el Fuero Juzgo ${ }^{5}$.

Además, una última observación: como podrá comprobar el lector, en la primera cita bibliográfica de cada autor dejo constancia de los datos completos relativos a su obra; en las siguientes notas me he permitido citar sólo de forma abreviada: esto es, el nombre del autor, la obra y la página correspondiente.

\section{La regulación en el Derecho romano}

\subsection{Consideraciones previas}

Como es sabido, el juez es una persona privada - iudex privatusquien es designado para resolver el litigio; esta intervención del iudex es la afirmación de la preeminencia y supervivencia del carácter puramente privado de la resolución de una controversia ${ }^{6}$. Se consiente la intervención pública (el magistrado competente) en la fase procesal in iure al objeto de pacificar lo que en su origen es un acto de violencia, y «es, tal vez, la violencia ritualizada la que otorga el punto de conexión para la intervención del poder público» ${ }^{7}$. Hay que tener en cuenta asimismo que todo iudex procuraría juzgar bien ${ }^{8}$ y honestamente como

4 «Lex Visigothorum», ed. ZeUMER, K., en Monumenta Germaniae Historica (Leges), vol. 1 (Hannover-Leipzig, 1902). En adelante, LV.

${ }_{5}^{5}$ La compilación legislativa, promulgada por Recesvinto, se la conoce por los diferentes nombres de Lex Visigothorum, Liber Iudiciorum o Liber Iudicum, cf. datos más concretos acerca de la citada Ley en la nota 88 del presente trabajo; debe destacarse, además, que la citada compilación se traduce al castellano en el siglo XIII con el nombre de Fuero Juzgo. En relación con el citado Fuero, se utiliza la edición de M. MARTínez Alcubilla, en Códigos Antiguos de España.

${ }^{6}$ El encargo de juzgar (iussum iudicandi) investía al juez de un deber oficial (munus iudicandi), que se concretaba en dar sentencia, entre otros, cf. GimÉnEZ-CANDELA, T., Derecho privado romano (Valencia, 1999), 156.

7 Cf. CRemades, I. y PARicio, J., «La responsabilidad del juez en el derecho romano clásico». Actio adversus iudicem qui litem suam fecit, en AHDE, 54 (1984), 189-190.

${ }^{8}$ La sentencia es la opinio, el sentire del juez, lo buscado por los litigantes, idem, 190. 
quisiera que se le juzgara a él, y, además, se tomaban precauciones exigiéndole un juramento. Antes de ser nombrado el juez debía prestar juramento de actuar bien ${ }^{9}$ - se refieren las fuentes al iudex iuratusque, si bien se le eximía de cualquier reclamación ulterior, no obstante le vinculaba en su fuero interno ${ }^{10}$. Además, el deber del juez, como se desprende claramente de las fuentes, es el de dar sentencia, una vez dictada deja de ser juez ${ }^{11}$.

De esta manera, su sentencia, fuera la que fuera, era ya intangible para el propio iudex, que no podía cambiarla, cf. por ejemplo, el texto de Alfeno en Dig. 42,1,62, donde se establece: Cum quaerebatur, iudex, si perperam iudicasset, an posset eodem die iterum iudicare, respondit non posse. Asimismo, un texto de Celso en Dig. 42,1,14, establece lo siguiente: Quod iussit vetiutvet praetor, contrario imperio tollere et remittere licet; de sententiis contra.

Por otra parte, aunque el deber de juzgar era irrenunciable y no hubo propiamente en el derecho clásico un sistema de excusas, no obstante podemos referirnos, por ejemplo, al texto de Ulpiano en Dig. 50,5,13, pr.-1, donde establece que el pretor excusará en determinados casos en los que entienda que no pueden prestarse a juzgar (por enfermedad, desempeño del sacerdocio...); asimismo en Dig. $4,8,13,4$, se permite que el juez pueda eximirse de dicha obligación mediante un juramento de no ver claro el asunto (iurare rem sibi non liquere).

Más concretamente, por lo que respecta al juez venal, la burocratización de la justicia en el procedimiento extraordinario ${ }^{12}$, acrecienta estos riesgos (la venalidad del juez) y la crisis de las costumbres, el debilitamiento del poder central y otras causas conexas, determinan un panorama desalentador ${ }^{13}$ del que nos ofrecen abundantes testimonios las fuentes, como los que se recogen en la constitución de Constantino del año 331 en CTh 1,16,714.

9 CJ 3,1,14 (año 531).

10 Cf. Cremades, I. y Paricio, J., La responsabilidad del juez en el derecho romano clásico, 185 y 190.

${ }^{11}$ Cf. el texto de Juliano en Dig. 5,1,74, pr.; asimismo, el texto de Ulpiano en Dig. $42,1,55$.

12 A partir del Principado (siglo I d. C.) y aplicado especialmente para el procedimiento extraordinario, en el que el litigio era fallado por un magistrado (y no por un iudex privatus) aparece un nuevo remedio contra la sentencia: se trata de la posibilidad de apelar ante un magistrado de rango superior a aquel que hubiera dictado la sentencia.

13 Vid. Alvarez Suárez, U., Curso de Derecho Romano. Tomo I, 610.

${ }^{14}$ CTh 1,16,7 Imp. Constantinus ad Provinciales. Cessent iam nunc rapaces officialium manus, cessent, inquam: nam nisi moniti non cessaverint, gladiis praecidentur. Non 
Los emperadores intentan en vano poner limitaciones a tal estado de cosas, proclamando que los jueces, en su misión, no deben dar entrada a otra cosa que la justicia, nihil aliud in iudiciis quam iustitiam habere debere, según se establece en una constitución del año 362 de los emperadores Diocleciano y Maximiano ${ }^{15}$ e invitando a las víctimas que han sido perjudicadas a que acudan a los tribunales, en los términos a los que se alude en la Constitución de Constantino del año 315 y que se recoge en el CJ 12,62,16, bajo el título: De lucris advocatorum et concussionibus officiorum seu apparitorum.

En definitiva, nos vamos a fijar en una serie de aspectos que tienen relación con la responsabilidad del juez en el ejercicio de su deber y concretamente:

1. En el cuasidelito del iudex qui litem suam fecit, el cual subsiste en la época justinianea.

2. En la obligación de resarcir de su propio patrimonio las costas procesales, si en la sentencia no dictó el oportuno pronunciamiento respecto de ellas.

3. En la responsabilidad penal que tiene ya regulación en las Doce Tablas. En todo caso, si el texto de PS 5,25,2 (= Coll. 8,5) nos vale para el derecho clásico, posteriormente, el caso del juez venal se había subsumido en el crimen falsi de la lex Cornelia, que no imponía la pena capital ${ }^{17}$

\subsection{Litem suam facere}

Como es sabido, en las res cottidianae la dicotomía contractus-delicta aparece reemplazada por una tripartición en los siguientes términos: toda obligación o nace de contrato, o de delito, o de cierto derecho

sit venale iudicis velum, non ingressus redempti, non infame licitationibus secretarium, non visio ipsa praesidis cum pretio. Aeque aures iudicantis pauperrimis ac divitibus reserentur. Absit ab iuducendo eius qui officii princeps dicitur depraedatio; nullas litigatoribus adiuditores eorundem officii principum concussiones adhibeant ...

15 Constitución recogida en CJ 7,62,6,1, que establece lo siguiente: Si quid autem in agendo negotio minus se allegasse litigator crediderit, quod in iudicio acto fuerit omissum, apud eum, qui de apellatione cognoscit, persequatur, quum votum gerentibus nobis aliud nihil in iudiciis, quam iustitiam locum habere debere, necessaria res forte transmissa non excludenda videatur.

${ }_{16}$ CJ 12,62,1, Imp. Constantinus ad Aelianum, Proconsulem Africae.- Si quis se a ducenariis vel centenariis vel fisci ad vocatis laesum esse cognoscit, adire iudicia et probare iniuriam non moretur, ut in eum, qui convictus fuerit, competenti severitate vindicetur.

17 Cf. D'Ors, «Litem suam facere» en SDHI, 48 (1982), 369, nota 3; cf. también los textos que se van a tratar más adelante. 
ex variis causarum figuris ${ }^{18}$. Después de mencionar una serie de supuestos $^{19}$, a continuación y siempre como variae causarum figurae, se mencionan, otros cuatro ilícitos ${ }^{20}$, entre ellos, el ilícito del juez qui litem suam fecit, cf. Dig. 44,7,5,4, supuesto al que nos vamos a referir en las siguientes líneas. Además, como es conocido, los cuatro supuestos ${ }^{21}$ mencionados juntos en las res cottidianae habían sido anteriormente sancionados por el edicto del pretor por medio de una serie de acciones con fórmula in factum concepta. ${ }^{22}$

Ya de forma más concreta y por lo que respecta al sentido técnico de litem suam facere ${ }^{23}$, podemos hacer alusión a una serie de testimonios: el más antiguo de todos ellos lo proporciona Macrobio, en Saturnalia, 3,16,14 y ss. y tiene relación con un discurso de Cayo Fannio en defensa de la lex Fannia, plebiscito del año 161 a. C. El citado orador se refiere a la jornada de los ciudadanos perezosos, que atienden de cualquier manera su deber cuando han sido elegidos jueces y van con desgana al Foro: ne litem suam faciant.

Otro testimonio nos presenta Aulo Gelio, Noctes Atticae, 10,1,524, con ocasión de la pregunta que se le formula acerca de los términos

18 Cf. el texto de Gayo, lib. 2. aureorum en Dig. 44,7,1,pr. Obligationes aut ex contractu nascuntur, aut ex maleficio aut proprio quodam iure ex variis causarum figuris.

${ }^{19}$ Los distintos tipos de causas que se mencionan son: La negotiurum gestio (cf. Dig. 44,7,5,pr.); la tutela (cf. Dig. 44,7,5,1); los legados obligacionales (cf. Dig. 44,7,5,2) y la solutio indebiti (cf. Dig. 44,7,5,3).

20 A continuación del ilícito del juez, se mencionan: el ilícito de arrojar sólidos o líquidos desde una vivienda causando daño, cf. Dig. 44,7,5,5; el ilícito de tener colocados en ventanas, balcones y tejados objetos cuya caída pudiera dañar a los transeúntes, cf. asimismo, Dig. 44,7,5,5; finalmente, los supuestos de hurtos y daños causados por los dependientes en los objetos introducidos en una nave, en una posada o en un establo, de los que respondían directamente los nautae, caupones y stabularii, cf. Dig. 44,7,5,6.

${ }^{21}$ La clasificación que aparece en las res cottidianae, se reproduce en las Instituciones de Justiniano, concretamente en Inst. 3,13,2, pero dividiendo el tercer grupo de obligaciones en dos: quasi ex contractu y quasi ex maleficio; el citado texto de las Instituciones se manifiesta en los siguientes términos: Sequens divisio in quattuor species diducitur: aut enim ex contractu sunt, aut quasi ex contractu, aut ex maleficio, aut quasi ex maleficio.

${ }^{22}$ La evolución en el caso del juez qui litem suam fecit debió ser muy similar a la que se produjo en el delito de injurias, ya que la regulación pretoria reemplazó a la regulación arcaica, ver, por ejemplo, PARICIO, J., Los cuasidelitos. Observaciones sobre su fundamento histórico (Madrid, 1987), 35. Sobre el juez que da sentencia injusta, véase también, RoBINSON, O., «The iudex qui litem suam fecerit explained», ZSS, 116 (1999), 195-199.

23 Algunos autores utilizan la expresión en sentido no técnico: así, por ejemplo, Cicerón, en De Oratore 2,305, establece, entre otras cosas: quid, si cum altero dicas, litem tuam facias, aut laesus efferare iracundia, causam relinquas: nihil ne noceas? También Séneca, en Consolatio ad Polybium (= Dial.12(11),2,2) dice entre otras cosas: Conqueramur, atque adeo ipse hanc litem meam faciam.

${ }^{24}$ Se cita por la collection «Les Belles Lettres», Tome II (Livres V-X) (París, 1978). 
tertium y tertio: no quiso abstenerse de dar juicio por no incurrir en el litem suam facere en que incurre el juez (según el texto) que se ausenta y no da sentencia.

Asimismo, el sentido técnico de litem suam facere aparece claramente en algunos textos de juristas:

En primer lugar, uno de los testimonios al que vamos a aludir procede de un texto de Ulpiano; se trata de un fragmento correspondiente al libro 12 ad edictum conservado en un papiro: el PAnt.2225, donde se establece: Item Pomp(onius) scr(ibit), si falso t(utore) a (uctore) male fuerit diffi(s)us dies, e(dictum) q(ui)dem cessare, et judicem q(ui)a neq(ue) diffidit neq(ue) s(ententi)am dixit litem suam fe[cisse.

Hacemos también mención a otro testimonio jurisprudencial que procede de Gayo 4,52, donde se establece lo siguiente en relación con el tema que nos ocupa: Debet autem iudex attendere, ut cum certae pecuniae condemnatio posita sit, neque maioris neque minoris summa posita condemnet: alioquin litem suam facit. Item, si taxatio posita sit, ne pluris condemnet quam taxatum sit: alias enim similiter litem suam facit; minoris autem damnare ei permissum est. De manera que, como dice el jurista, cuando la condemnatio de la fórmula es certa y el juez condena a más o menos de esa cantidad, litem suam facit, según el citado texto; las mismas consecuencias se producirían en el caso de que el pretor hubiera señalado una taxatio y el juez, desobedeciendo la orden pretoria, condenara a una cantidad superior a lo tasado. Precisamente a propósito del texto mencionado, considera $\mathrm{Kaser}^{26}$ que en esos supuestos la sentencia sería nula, aún reconociendo que el autor del texto nada establece al respecto. En esta misma línea se pronuncia $\mathrm{D}^{\prime} \mathrm{Ors}^{27}$ cuando considera que «el juez que no se ajusta a la fórmula no da sentencia alguna», y añade seguidamente que «el dar una sentencia nula equivale a no dar sentencia».

Otro testimonio acerca de la citada responsabilidad del juez tiene relación con un texto legal, concretamente con la lex municipii Flavi Irnitani $^{28}$, copia de la lex Flavia municipalis. Precisamente, la publica-

25 Se trata de un texto fragmentario, publicado por RoBerts en The Antinoopolis Papiry Part I (London, 1950), 47-51. Véase también, el comentario de ARANGIO-RuIZ en IURA, 2 (1951), 344 ss. Hay que tener en cuenta asimismo lo que establece SEIDL, E., en SDHI, (1952), 343, que no se trataría de un ejemplar del ad edictum de Ulpiano, sino de una antología de fragmentos de diversos juristas clásicos.

26 KASER, en ZSS, 84 (1967), 517, nota 36.

27 D’Ors, A., «Litem suam facere», en SDHI, 48, (1982), 372.

28 «Lex Irnitana» (texto bilingüe) de Alvaro d'Ors y Javier d'Ors en Cuadernos compostelanos de Derecho romano. (Universidad de Santiago de Compostela, 1988). 
ción del artículo: Litem suam facere, del profesor D’Ors ${ }^{29}$, «replantea, y en buena medida aclara una serie de complejos problemas referidos en último término a la responsabilidad privada del juez romano» ${ }^{30}$. El citado artículo da una interpretación diferente de la que mantenían autores anteriores ${ }^{31}$ acerca del iudex qui litem suam fecit.

Concretamente el texto legal mencionado trata del intertium, de la diffissio y del juez que, por no hacer bien la diffissio ni dar sentencia, asume en propio perjuicio la causa, que deja de estar en juicio. Hay que destacar además que la expresa referencia al régimen urbano, que se observa en los municipios por analogía, permite deducir, según D'Ors ${ }^{32}$, que no se trata de un particularismo provincial, sino de derecho propiamente «romano» lo que da mayor importancia a la nueva información. Más concretamente, la mencionada ley viene a completar la escasa documentación sobre la diffissio, «que quizá puede convertirse ahora en una institución del procedimiento civil romano más relevante de lo que suele aparecer en las exposiciones ordinarias $»^{33}$.

De esta manera, además de los testimonios anteriores sobre el tema, se añade ahora un nuevo dato aportado por la lex Irnitana ${ }^{34}$. Concretamente, en la citada lex Irnitana, se establece que el litigio «sea en daño para el juez o para el árbitro», si no se hizo la diffissio ni dictó sentencia:

Tabla X, col. A, lín. 52 ss: ... et si neque dies diffisus neque iudicatum fuerit, uti lis iudici arbitrove damni sit et... res in iudicio non sit. ${ }^{35}$

Tabla X, col. B, lín. 15 ss.: Utique si neque diffisum e lege neque iudicatum sit... iudici arbitrove lis damni sit..., si... iudicatum non sit, res in iudicio non sit. ${ }^{36}$

29 «Litem suam facere», 368 ss.

30 Vid. Cremades y Paricio, J., «La responsabilidad del juez en el Derecho romano clásico». Actio adversus iudicem qui litem suam fecit, 179.

31 Idem, 179-180: véase la bibliografía contenida en las notas 2 y 3.

32 Cf. D’Ors, A., «Litem suam facere», 376.

${ }^{33}$ Idem, 376.

${ }^{34}$ De nuevo vuelve sobre la citada ley, D'Ors, «Nuevos datos de la lex Irnitana sobre jurisdicción municipal», en $S D H I, 49$ (1983), 18 ss., con fundamento en fotografías de los bronces; asimismo, una información del mismo autor más sucinta: Idem, «La nueva copia irnitana de la «lex Flavia municipalis», en AHDE, 53 (1983), 5 ss.; véase también sobre la citada lex, GimÉnez-CANDEla, «La "lex Irnitana". Une nouvelle loi municipale de la Bétique», en RIDA, 30 (1983) 125 ss.

35 Cf. Lex Irnitana. Texto bilingüe de Alvaro d'Ors y Javier d'Ors, 79.

${ }^{36}$ Cf. Lex Irnitana, idem, 81. 
El mencionado contenido de la lex coincide con los testimonios jurisprudenciales más fidedignos acerca del litem suam facere y, en especial, el testimonio de Ulpiano en PAnt. 22 (citado supra), donde, entre otras cosas, como se ha visto anteriormente, establece: et judicem qui neque diffidit neque sententiam dixit litem suam fecisse.

Hacemos mención seguidamente a otro de los textos jurisprudenciales que tiene relación con la materia a la que nos estamos refiriendo; se trata de un texto de Gayo que procede del libro 3 de las res cottidia$n a e^{37}$, contenido en Dig. 44,7,5,4 = Dig. 50,13,6 y transcrito en las Instituciones de Justiniano, concretamente en Inst. 4,5,pr. El citado texto tiene el siguiente contenido:

Si iudex litem suam fecerit, non proprie ex maleficio obligatus videtur; sed quia neque ex contractu obligatus est, et utique pecasse aliquid intellegitur, licet per imprudentiam, ideo videtur quasi ex maleficio teneri in factum actione, et in quantum de ea re aequum religioni iudicantis visum fuerit poenam sustinebit ${ }^{38}$.

En el texto transcrito, vemos que se deja clara constancia sobre la acción que estaba concebida in factum ${ }^{39}$; independientemente de si se puede o no hablar de intentio para las fórmulas in factum ${ }^{40}$, hay que plantearse la cuestión acerca de qué factum se alegaba por el demandante en este tipo de acción. En realidad, el factum que se le podía reprochar era el de no haber dado sentencia; quien no cumple con su deber de dar sentencia carga sobre sí las consecuencias que hubiera podido tener el litigio que él dejó de decidir. Como se ha dicho anteriormente el juez, si tenía razones para un aplazamiento, debía haber hecho la diffissio y si no la hizo ni tampoco juró rem sibi non liquere, debe asumir las consecuencias; es el riesgo propio del que ha sido nombrado juez ${ }^{41}$.

Hay que destacar asimismo que el término imprudentia al que alude el mencionado texto de las res cottidianae, esto es -licet per im-

37 El citado texto se considera menos relevante para determinar el sentido de la expresión litem suam facere, así como el tipo de acción, cf. D’Ors, A., Litem suam facere, 387.

38 Precisamente, el párrafo final: et in quantum de ea re aequum religioni iudicantis visum fuerit poenam sustinebit, no está en el texto de Gayo en Dig. 44,7,5,4.

39 No era una acción penal, cf. D’ORs, A., «Litem suam facere», 381.

40 Vid. VAliño en Estudios jurídicos en homenaje al Profesor U. Alvarez Suárez, (Madrid, 1978), 519.

${ }^{41}$ Cf., por ejemplo, D’ORs, A., «Litem suam facere», 387. 
prudentiam - no es un término técnico del derecho y puede tener distintas acepciones, pero en su sentido especial, no significa más que falta de prudentia. La imprudentia de un juez, considera D'Ors ${ }^{42}$, no tiene que ver necesariamente con su culpa, sino más generalmente con su ignorancia ${ }^{43}$. Todo ello le lleva a decir al autor que, aunque la responsabilidad objetiva puede entenderse mejor cuando se refiere a actos de otra persona «creemos que es acertada la opinión que hoy parece dominante en la doctrina, de admitir tal responsabilidad en el iudex qui litem suam fecit» ${ }^{44}$; sigue diciendo además el autor mencionado que «esto resulta todavía más claro si entendemos que el $l i$ tem suam facere es la consecuencia del simple factum de no haber dado una sentencia, es decir, por simple omisión del juez, y no por su injusticia» ${ }^{45}$.

Otro aspecto además que interesa destacar del citado texto es a propósito de la posición que la figura del litem suam facere ocupa en la categoría de los cuasidelitos en la sistemática postclásica. Como es sabido, en la sistemática de las Instituciones de Justiniano, se alude a los cuatro cuasidelitos y concretamente, el libro 4, título 5, lleva la siguiente rúbrica: De obligationibus quae quasi ex delicto nascuntur. Precisamente el primer supuesto que en las fuentes aparece colocado delante de los demás, concretamente, en Inst. 5,4,pr. es el del iudex qui litem suam fecit ${ }^{46}$; en Inst. 5,4,1, se presenta otro supuesto, si... deiectum effusumve aliquid est ita ut alicui noceretur; en el mismo párrafo citado, se encuentra el supuesto, is qui ea parte qua vulgo iter fieri solet id positum vel suspensum habet quod potest, si ceciderit, alicui nocere.; finalmente, en Inst. 5,4,3: Item execitor navis aut cauponae aut stabuli de dolo aut furto, quod in navi aut caupona aut stabulo factum erit. Además, como es sabido, esta categoría de los cuasidelitos procede de las res cottidianae de Gayo, recogida en Dig. 44,7,5,4, con la diferencia también sobradamente conocida de que el quasi ex maleficio teneri que aparece en Gayo, da

42 D'ORs, A., «Litem suam facere», 389.

43 Así, por ejemplo, cuando Cicerón, Verr. 2,23,57, establece: saepe per imprudentiam fit; asimismo en algunos textos del Digesto: Dig. 2,2,2, cuando un magistrado sigue el consejo erróneo de su asesor: nam si assessoris imprudentia..., dice el texto; y también en Dig. 21,2,51 pr. se habla de imprudentia iudicis, a propósito de un juez que ocasiona de forma errónea la evicción de un comprador.

4 Cf. D’ORs, «Litem suam facere», 390.

45 Ibidem.

46 El caso del iudex, que aparece en primer lugar, es el caso-guía y puede orientarnos acerca de la razón que ha llevado a constituir la categoría del cuasi-delito, cf. D'Ors, A., «item suam facee», 392. 
lugar en la rúbrica de las Inst. 4,5 a la categoría de las obligaciones que surgen quasi ex delicto.

Llegados a este punto, puede estimarse muy razonable la opinión que considera que lo que da unidad a la categoría de los cuasidelitos es precisamente lo que se ha considerado como responsabilidad objetiva ${ }^{47}$. Concretamente, en el supuesto del iudex, el motivo de su responsabilidad es la omisión de sentencia, el incumplimiento de un $m u$ nus, independientemente de toda consideración de dolo o culpa ${ }^{48}$. La dogmática moderna, se refiere en estos casos a una responsabilidad objetiva, «pero desde el punto de vista del Derecho romano clásico esta particularidad debe explicarse mejor en consideración al tipo de acción» ${ }^{49}$.

De esta manera, lo que llamamos responsabilidad objetiva, no es más que el efecto de que la actio in factum correspondiente no presupone el dolo malo del demandado y conduce a una condena por el simple factum que se le imputa: concretamente, en el caso del iudex, el haber dejado de dar sentencia.

Además del texto de Ulpiano conservado en un papiro (en el PAnt. 22), citado supra, nos vamos a referir a continuación a otro texto atribuido al mismo jurista y recogido en este caso en Dig. 5,1,15,1. El contenido del texto es el siguiente:

Iudex tunc litem suam facere intellegitur cum dolo malo in fraudem legis sententiam dixerit (dolo malo autem videtur hoc facere si evidens arguatur eius vel gratia vel inimicitia vel etiam sordes) ut veram aestimationem litis praestare cogatur.

Se trata de un texto muy complejo que ha sido objeto de numerosas interpretaciones ${ }^{50}$. Ahora bien, a propósito del mencionado texto el profesor A. D'Ors ${ }^{51}$ además de establecer que no puede atribuirse a Ulpiano, considera asimismo como completamente glosemático el citado fragmento, «que sería la causa de todos los errores sobre nuestro tema» ${ }^{52}$.

47 Cf. Hubner, Heinz, «Zur Haftung des iudex, qui litem suam fecit», en IURA, 5 (1954), 207.

48 D'ORs, Litem suam facere, 393.

49 Idem, 394. Considera además el autor citado que muchas acciones in factum se refieren expresamente al dolo malo del demandado, pero cuando no es así, hay que pensar en una responsabilidad objetiva del mismo, ibidem.

50 Cf., entre otros, PARICIO, J., Los cuasidelitos. Observaciones sobre su fundamento histórico, 41.

51 En «Litem suam facere», 377.

52 D'ORs, «Litem suam facere», 373. Establece asimismo el citado autor que por litem suam facere debe entenderse exclusivamente el hecho de que un juez se subroga en lugar 
No obstante lo anterior, a juicio del profesor Paricio ${ }^{53}$ cabe salvar el sentido que Ulpiano da en el texto a la expresión litem suam facere: «en efecto - considera el autor-, para poder detectar una actuación del juez en fraude de ley (o contra ley) es absolutamente necesario que exista la posibilidad de revisar las sentencias, que exista en último término apelación, cosa posible con carácter general por vía extraordinaria, desde la segunda mitad del siglo II d. C., no antes». A esto anterior hay que añadir como dice el mencionado autor «que como Ulpiano escribe en un momento histórico en el que la revisión de las sentencias de los jueces privados resultaba posible, es probable que extendiera en el sentido del texto el ilícito de litem suam facere ${ }^{54}$.

En definitiva, se puede considerar que los testimonios anteriores, salvo el texto de Ulpiano en Dig. 5,1,15,1, que acabamos de ver, vienen en el fondo a identificar litem suam facere con ausencia de sentencia.

A modo de resumen, la idea central consiste en señalar que un juez litem suam facit cuando no da sentencia, a lo que queda asimismo equiparado el dictarla fuera de los límites de la fórmula, ya que tal sentencia sería nula ${ }^{55}$ y equivaldría a ausencia de sentencia. Por lo tanto, el factum alegado en la intentio in factum de la fórmula correspondiente a la actio adversus iudicem qui litem suam fecerit sería la ausencia de sentencia, «lo que cuadraría con los otros tres supuestos que serían llevados por Justiniano a la categoría cuasi-delictual apoyándose en un sistema de responsabilidad objetiva» ${ }^{56}$. Por otra parte, al indicar D'Ors ${ }^{57}$ que el juez que hizo suyo el litigio se subrogaba en la posición del demandado, señala que la condemnatio de la fórmula edictal quizá hiciera referencia a in quantum Lucius Titius (el demandado en la acción frustrada) condemnari debuisset.

del demandado cuando deja incumplido su deber de dar sentencia en el momento en que había de hacerlo o, lo que es lo mismo, cuando da una sentencia, no injusta, sino nula, idem, 369.

${ }^{53}$ PARICIO, Los cuasidelitos. Observaciones sobre su fundamento histórico, 42.

54 Ibidem.

55 En esos casos el juez se subroga en lugar del demandado cuando deja incumplido su deber de dar sentencia en el momento en que había de hacerlo,o, lo que es lo mismo, cuando da una sentencia, no injusta, sino nula.

56 Cf. Cremades, I. y PARICIO, J., «La responsabilidad del juez en el derecho romano clásico». «Actio adversus iudicem qui litem suam fecit», AHDE, 54 (1984), 180.

57 «item suam facere», 391. 


\subsection{Gastos procesales}

Determinados textos jurisprudenciales, así como algunas constituciones imperiales, nos dan testimonio acerca de los gastos procesales.

Así, pues, se puede imputar responsabilidad al juez, haciéndole pagar las costas procesales ${ }^{58}$ en los términos a los que nos vamos a referir, no sin antes señalar que los gastos procesales en un procedimiento exclusivamente oral, quedaban reducidos a los que causaran los medios de prueba y a los prudentes y módicos honorarios de los procuradores, abogados y oradores, siendo soportados por cada una de las partes que los hubiera causado ${ }^{59}$. Más adelante, la instauración de la cognitio extraordinem como procedimiento normal trae consigo un gran aumento de las costas procesales ${ }^{60}$. Se comprende por ello que comenzara a nacer la idea de considerar injusto que soporte las costas judiciales el litigante asistido de razón que se ha visto precisado a seguir un pleito para que le sea reconocida, iniciándose de este modo el nuevo principio de que soporte las costas aquella de las partes que pierda el litigio (principio del vencimiento); determinados textos del Digesto ${ }^{61}$ reflejan la exigencia de imponer las costas al demandante que ha sido vencido, en base a la temeritas en que incurrió al reclamar por medio de la actio correspondiente. Más adelante, se aplica el principio del vencimiento al demandado que pierde el pleito, después de haberse opuesto injustificadamente a la demanda ${ }^{62}$; de la misma manera, rige el mismo principio

$58 \mathrm{Ni}$ en el procedimiento de las acciones de ley, ni en el formulario, ha habido necesidad de fijar la atención sobre los gastos procesales, porque puede decirse que en ellos apenas existían, cf. Alvarez SuÁrez, Curso de Derecho romano. Tomo I, 604.

59 Entre otros, cf. Alvarez, Curso de derecho romano, 604. Este principio de la justicia gratuita, que trae consigo el deseable acceso de todos los ciudadanos a los tribunales para el amparo de sus derechos, conduce también al riesgo de que se litigue sin un serio fundamento, recargando sin causa justificada el trabajo del órgano jurisdiccional, Ibidem.

${ }^{60}$ La oficina del magistrado (el officium), integrada por numerosos miembros (la mayor parte militares destinados a prestar en ella sus servicios), originaba cuantiosos gastos que se atendían por el cobro de determinados derechos a las partes (sportulae), en relación con los servicios prestados y con la importancia de la cuestión litigiosa; hay que señalar, además, que como la intervención oficial en el procedimiento extraordinario es decisiva, devengaban derechos las citaciones, la redacción de actas y escritos, la expedición de certificaciones de sentencias, las apelaciones, etc. Todos estos devengos, aunque sometidos a tasas legales, producían sumas considerables.

61 Cf. algunos textos: Dig. 5,1,79, y 50,5,1,1; asimismo, Dig. 31,78,2.

62 Cf., por ejemplo, una constitución de Valentiniano del año 369, contenida en CTh. $4,18,1$, donde se establece lo siguiente: Addimus etiam, ut impensas sumptusque litis, re ad finem deducta, petitoribus praestent. 
para quien pierde una apelación que se ha interpuesto de forma injustificada; todavía subsiste el citado criterio, un tanto mixto, en la imposición de las costas procesales en la época justinianea, de manera que es mencionado en sus Instituciones, concretamente en Inst. 4,16: De poena temere litigantium.

$\mathrm{Si}$ en las épocas anteriores se fueron estableciendo los mencionados criterios, se ha de destacar que a partir de una constitución de Zenón del año 487, empieza a imponerse ${ }^{63}$ el principio duro y simple de que las costas procesales debe soportarlas, íntegra y exclusivamente el litigante vencido ${ }^{64}$, siguiéndose la máxima victus fert expensas (el vencido sufre las costas). De tal manera que el juez debe declarar en la sentencia de forma expresa quién de las dos partes litigantes ha de soportar todos los gastos ocasionados en el proceso, como se establece en la constitución de Justiniano del año $530^{65}$; hay que tener en cuenta además que como durante la tramitación del litigio no se conocía aún a quién correspondía pagar, cada parte debía ir satisfaciendo las costas que se iban produciendo en cada uno de los trámites. Ahora bien, una vez dictada la sentencia, la parte victoriosa fijaba, mediante juramento, el importe de las costas que había satisfecho, y esta declaración determinaba el límite máximo de la cantidad con que el condenado había de resarcirle. Además, para hacer efectiva la citada indemnización se seguían las reglas de la ejecución en general. Si el juez omitía el pronunciamiento sobre las costas o el ejecutor no lo cumplía, habían de realizar ellos mismos el resarcimiento con sus propios bienes, según se

${ }^{63}$ Consideraciones acerca de las costas procesales. Los principios de la temeridad y del vencimiento, en el contexto histórico del derecho romano, puede verse en Alvarez SuÁREZ, Curso de Derecho romano, 604 ss.

${ }^{64} \mathrm{Se}$ recoge el Epitome de la constitución griega de Zenón, tomado de las Basilicas en CJ 7,51,5,pr, donde se establece: Constitutio sancit, ut omnis iudex in sententia sua iubeat victum praestare omnes expensas in iudicio erogatas; concessa ipsi iudici potestate et excedendi summam expensarum ad decimam usque partem eorum, quae impensa sunt, si eum victi impudentia ad hoc permoverit, ita ut id, quod expensas excedit, ad publicas rationes pertineat, nisi forte iudex, morae detrimentum parti victrici sarcire volens, partem aliquam eoum ei addicat; condemnando non solum actore et reo, si iudex utrique competens sit, verum etiam si actori sit incompetens, si is vincatur ex reconventione, quum non possit illum iudicem recusare, sive praesides iudices fuerint, sive delegati a principe arbitri; nam et hi executores et compulsores habent. Quodsi iudex hoc non fecerit, ipse hoc damnum victrici parti sarcire cogitur.

${ }^{65}$ CJ 3,1,13,6, donde se establece lo siguiente: Sive autem alterutra parte absente, sive utraque praesente lis fuerit decisa, omnes iudices, qui sub imperio nostro constituti sunt, sciant in expensarum causa victum victori esse condemnandum, quantum pro solitis expensis litium iuraverit, non ignorantes, quod, si hoc praetermiserint, ipsi de proprio huiusmodi poenae subiacebunt et reddere eam parti lesae coartabuntur. 
establece asimismo en la Constitución de Justiniano del 530 recogida en el CJ $3,1,15^{66}$.

\subsection{La responsabilidad penal}

Sobre el juez venal tenemos un testimonio que nos proporciona Aulo Gelio $^{67}$ y que corresponde al texto legal de las XII Tablas 9,368, según el cual se castigaba con la pena de muerte al juez convicto de haber aceptado dinero para pronunciar sentencia. Más tarde, el caso del juez venal se había subsumido en el crimen falsi de la lex Cornelia, que no imponía la pena capital. Se trata de la lex Cornelia, de la época de Sila, que recibe el nombre de lex Cornelia testamentaria nummaria. Las fuentes la designan en otras ocasiones, lex Cornelia de testamentis y lex Cornelia de falsis, aunque esta última designación correspondería a una época posterior $^{69}$. Tiene relación la citada ley con las injusticias que se cometían en materia de testamentos y del comercio monetario. La asociación en una misma ley de la falsificación de testamentos, de sellos y de monedas es muy explicable: el elemento común era el abuso del signum. La mencionada lex Cornelia continuó vigente aún en las épocas posteriores y lo único que se hizo fue ampliar por medio de disposiciones concretas ${ }^{70} \mathrm{el}$ número de casos comprendidos en la misma, entre ellos:

66 CJ 3,1,15 del emperador Justiniano al Prefecto del Pretorio.- Sancimus, omnes iudices, sive in hac florentissima civitate sive in provinciis, si quando absens persona citata postea apparuerit, non aliter ei iudicialem aditum revelare, sed omnem claudere ei iudiciorum copiam, nisi prius omnia damna restituat, ex huisusmodi vitio adversariis eius inflicta sive circa ingressus litis, sive circa honoraria advocatorum vel alias causas, quae in iudicio vertuntur; aestimatione iudicis quantitate eorum definienda, postquam iuratum ab eo fuerit, qui fecit expensas; exsecutoribus negotiorum modis omnibus dispositiones eorum adimplentibus, scituris iudicibus nostris et exsecutoribus, quod, si hoc praetermiserint, ex sua substantia huiusmodi detrimentum laesis resarcire compellentur. Quod et in pedaneis iudicibus abservari censemus; licet non citati, sed requisiti litigatores mala conscientia abfuerint.

${ }^{67}$ Noct. Att., 20,1,7. En relación con el citado testimonio de Gelio, establece D’ORs, «Litem suam facere», 369, que debe tomarse con suma cautela; considera además que probablemente el precepto decenviral (XII Tablas 9,3) si realmente existió, se refería a un juez que ha condenado, por dinero, a un reo criminal, ibidem.

68 Cf. Tabla 9,3.-Gellius 20,1,7: duram esse legem putas, quae iudicem arbitrumve iure datum, qui ob rem \{iu\}dic\{a\}ndam pecuniam accepisse convictus est, capite poenitur?

69 Cf. Dig. 48,10; Inst. 4,18,7; CJ 9,22; CTh 9,19. Con relación a la fecha de la citada ley, en la actualidad parece aceptarse el año 81 a. C. con lo que resultaría coetánea de otra ley Cornelia contra sicarios y envenenadores: Lex Cornelia de sicariis et veneficiis, cf. PS 5,23; Dig. 48,8; CJ. 9, 16.

70 Una ampliación notable vino a alcanzarse en virtud de los senadoconsultos que mencionamos a continuación: sc. Liboniano, que llegó a extender a otros documentos 
1. El juez que, conscientemente o por negligencia, pronunciara sentencia en contra de las Constituciones del Príncipe ${ }^{71}$ o del Derecho público que ante él se invocara, era castigado con pena de destierro en una isla, según establece el texto de las PS 5,25,4: Iudex, qui contra sacras principum contitutiones contraue ius publicum, quod apud se recitatum est, pronuntiat, in insulam deportatur.

2. Incurren en igual delito y sanción el juez que recibiera dinero para pronunciar o no pronunciar sentencia, y la persona que se lo entregara, en los términos que seguidamente vamos a mencionar.

Podemos referirnos concretamente a una serie de textos que tienen relación con la posible conducta dolosa del juez. Así, en un texto de Marciano, en Dig. 48,10,1,2 $2^{72}$ es condenado con la pena de la ley Cornelia $^{73}$ el juez que es corrompido, así como el que hubiere corrompido al juez. De manera que con el tiempo acaba por aproximarse al falsum el soborno del juez, como vemos, asimismo, en PS 5,25, ${ }^{74}$ : iudicemve ut sententiam ferat vel non ferat corruperit corrumpendumve curaverit. Establece, además, el texto citado diferente pena con base en la diversa categoría social ${ }^{75}$ de la persona que soborna.

no testamentarios lo que la ley Cornelia había previsto para el acto de scribere, signare o recitare un testamento falso, pero no otro tipo de abuso en documentos auténticos; por lo que respecta al sc. Mesaliano, vino a someter a la pena de la ley Cornelia los que cobraban, pactaban o se asociaban para preparar abogados o testigos contra alguien, o se asociaban para complicar en procesos a personas inocentes; el sc. Geminiano sometió a la misma pena a los que cobraban por citar, no citar o despedir a un testigo ya citado, así como los testigos que cobraban por declarar o no su testimonio: se penaba la venalidad, independientemente de la falsedad, cf., por ejemplo, D’Ors, A., «Contribuciones a la historia del crimen falsi», Studi in onore di Edoardo Volterra, II (Milano, 1971), 646.

71 Cf. Dig. 48,10,1, 3: Sed et si iudex Constitutiones Principum neglexerit, punitur.

72 Dig. 48,10,1,2, el texto de Marciano: Sed et si quis ob renuntiandum remittendumve testimonium, dicendum vel non dicendum pecuniam acceperit, poena legis Corneliae afficitur, et qui iudicem corruperit corrumpendumve curaverit.

${ }^{73}$ La ley Cornelia relativa a las falsedades, cf. Dig. 48,10.

${ }_{74}$ PS 5,25,2 = Coll. 8,5,1, donde se establece lo siguiente: Qui ob falsum testimonium perhibendum uel uerum non perhibendum pecuniam acceperit dederit iudicemue, ut sententiam ferat uel non ferat, corruperit corrumpendumue curauerit, humiliores capite puniuntur, honestiores publicatis bonis cum ipso iudice in insulam deportantur.

75 Sobre ello, ver por ejemplo: GARNSEY, P., Social status and legal privilege in the Roman Empire (Oxford, 1970), 103-178; También, DE RoBERTIS, F.M., «La variazione della pena pro qualitate personarum nel diritto penale romano», RISG, 14 (1939), 1-54; véase asimismo, CARDASCIA, G., «L'apparition dans le droit des classes d'honestiores et d'humiliores», en RHDFE, 28 (1950), 305-337 y 461-485. 
Concretamente, si el que entrega dinero pertenece a la clase de los humiliores, es condenado a muerte; si pertenece a la de los honestiores, sufre la confiscación de sus bienes y destierro a una isla, como el juez. La pena, según establece el mencionado texto, se extendería al mismo juez (cum ipso iudice).

Asimismo, es sancionado con la pena de falsificación, según un texto de Paulo en Dig. 48,10,2176, el que soborna a un juez y se impone otra clase de sanción en PS 5,16,12, ya que se castiga al que compró una sentencia absolutoria con la condena que hubiera podido recaer sobre él por el crimen de que se le inculpaba.

A partir de la citada ley Cornelia establece Mommsen una serie de grupos de los actos conminados con penas, ora por la propia ley Cornelia, ora por las ampliaciones a que se la sometió ${ }^{77}$. Ahora bien, con relación a la fecha en que se produjo la aproximación del soborno judicial al falsum, considera D'Ors ${ }^{78}$ que no es anterior a mediados del s. III. Alega el citado autor una serie de argumentos. En primer lugar, el texto de Marciano, citado supra, y contenido en Dig. 48,10,1,2, parece extender ya la pena del falsum (poena legis Corneliae) a qui iudicem corruperit corrumpendumve curaverit y el texto citado de Paulo en Dig, 48,10,2179, como hemos visto, establece, entre otras cosas: iis adiungitur et is qui iudicem corrumpit; ahora bien, según D'Ors, estos dos incisos quizá deban atribuirse a una época posterior a la de los autores de sendos textos ${ }^{80}$. Aparte estos reparos formales, presenta el autor otros argumentos de que esa extensión del falsum a la corrupción judicial, activa y pasiva, no es anterior a mediados del s. III; se trata de dos rescriptos que aplican otra pena distinta: uno de los rescriptos, re-

76 El texto de Paulo en Dig. 48,10,21, establece: Qui duobus in solidum caudem rem diversis contractibus vendidit, poena falsi coercetur; et hoc et Divus Hadrianus constituit. Iis adiungitur et is, qui iudicem corrumpit; sed remissius puniri solent, ut ad tempus relegentur, nec bona illis auferantur.

77 Mommsen, T., Derecho penal romano. Trad. del alemán por P. Dorado (Bogotá, 1976), 420, establece los grupos siguientes: I) Delitos de falsificación de testamentos y de documentos. II) Delitos de falsificación de metales preciosos y de moneda. III) Delitos procesales y delitos cometidos por los abogados. Dentro del citado grupo estarían una serie de actos: 1) Pronunciar un fallo, a sabiendas de que se infringía una ley clara. 2) Proponer al juez que aceptase dádivas o aceptarlas éste para dar o no dar un determinado fallo. 3) Entrar en inteligencias para lograr la condena de un inocente... IV) falsificación del parentesco o de la condición de la persona. V) Falsos pesos y medidas.

78 D’Ors, A., «Contribuciones a la historia del crimen falsi», 556.

79 Cf. la nota 76.

80 D’ORs, A., «Contribuciones a la historia del crimen falsi», 556 según el citado autor, «el inciso del texto de Marciano aparece como un añadido a un precedente con el que no tiene relación...», ibidem. 
ferido en un texto de Macro en Dig. 49,14,3481, corresponde a Severo y Caracala a Asclepiades y castiga al que sobornó a un juez con una pena pecuniaria del todo extraña a la del falsum — quinientos sueldos para el fisco- . El otro rescripto, al que precisamente alude Ulpiano en Dig. 3,6,1,382, y conservado en CJ 7,49,183, pertenece a Caracala y habla en ese caso de soborno, de pérdida de litigio..., en todo caso, estos dos rescriptos parecen ignorar toda aproximación del soborno judicial al falsum. La extensión se habría producido tan sólo a mediados del s. III $^{84}$.

Nos referimos finalmente a otro de los textos pertenecientes a las Sentencias de Paulo, y relativo al soborno del juez, concretamente en PS $5,23,11(10)^{85}$ señala para el juez venal que da sentencia injusta in caput fortunasque hominis la pena de destierro y de confiscación de bienes (in insulam bonis ademptis deportatur). Esta era la pena del homicidio, y por ello se trata de este delito en el título 23: ad legem Corneliam de sicariis et veneficiis, y precisamente a continuación de un párrafo PS $5,23,10(11)$, donde se establece que: mandatores caedis perinde ut homicidae puniuntur. Tal pena resultaba racional en el caso de sentencia que condenaba injustamente a una pena capital (pues en ese caso el juez resultaba mandator caedis), pero no ya si la condena era patrimonial ${ }^{86}$.

81 Dig. 49, 14,34: Imperatores Severus et Antoninus Asclepiadi ita rescripserunt: «Tu, qui defensione omissa redimere sententiam maluisti,quum tibi crimen obiiceretur, non immerito quingentos solidos inferre fisco iussus es; omissa enim ipsius causae inquisitione ipse te huic poenae subdidisti; obtinendum est enim, ut hi, quibus negotia fiscalia moventur, ad defensiones causae bona fide veniant, non adversarios aut iudices redimere tentent».

82 El texto de Ulpiano en Comentarios al Edicto, libro 10, recogido en Dig. 3,6,1, 3 : Sed et Constitutio Imperatoris nostri, quae scripta est ad Cassium Sabinum, prohibuit iudici, vel adversario in publicis, vel privatis, vel fiscalibus causis pecuniam dare; et ex hac causa litem perire iussit. Nam tractari potest, si adversarius non per calumniam transigendi animo accepit, an Constitutio cessat? Et puto cessare, sicuti hoc quoque iudicium; neque enim transactionibus est interdictum, sed sordidis concussionibus.

${ }^{83}$ Hay un error evidente en el citado rescripto según se recoge en el Digesto, ya que el nombre del destinatario en el Código de Justiniano es ad Gaudium, mientras que en el Digesto va dirigido ad Cassium Sabinum.

${ }^{84}$ Cf. D’Ors, A., «Contribuciones a la historia del crimen falsi», 557.

85 En PS 5,23,11 (10), se establece lo siguiente: Iudex, qui in caput fortunasque hominis pecuniam acceperit, in insulam bonis ademptis deportatur.

86 Según D’Ors, «El Código de Eurico» en Estudios visigóticos, II (Roma-Madrid, 1960), 59, es un rasgo destacado de la legislación Euriciana el de la desaparición de las penas de deportación en todas sus formas; esto era muy explicable, sigue diciendo el autor, pues el territorio gobernado por Eurico acababa de ampliarse y se iba a ampliar más, de suerte que, ni las fronteras resultaban muy ciertas, ni existía probablemente un sistema de vigilancia suficiente para impedir el incumplimiento de tal tipo de condena. 


\title{
3. La regulación en el derecho visigodo ${ }^{87}$
}

\author{
3.1. $L a$ Lex Visigothorum ${ }^{88}$
}

\subsubsection{CONSIDERACIONES PREVIAS}

El libro 2 de la Lex Visigothorum ${ }^{89}$ (de negotiis causarum) ${ }^{90}$ contiene cinco títulos, referentes todos ellos, de forma más o menos directa, al proceso.

87 El reino visigodo antes de su establecimiento definitivo en Occidente, se constituyó en estrecha relación con el Imperio, al que desde antiguo venía prestando servicios militares de frontera bajo la fórmula del foedus (cf. GIBERT, Rafael, «El reino visigodo y el particularismo español», en Cuadernos del Instituto Jurídico español, 5. Estudios visigóticos, I (Roma-Madrid, 1956), 7 y las notas 6 y 7. El primer período del asentamiento de los visigodos en las Galias y en la parte noroeste de la Península, dominio que por el Occidente llegó al parecer hasta Zaragoza, se inscribe en la estructuración del Imperio Romano, en la etapa anterior a la caída de Roma por los hérulos (cf. entre otros OrLANDIS, J. Historia de España. La España visigótica. (Madrid, 1977), 59 ss. GarCía Gallo, A., «Consideración crítica de los estudios sobre la legislación y la costumbre visigoda» en $A H D E$, (1974), 424 ss. A partir del año 476, con la entrada de Odoacro en Roma, la situación sufrió transformaciones profundas que se manifestaron de forma desigual en los distintos territorios sobre los que estaban asentados los visigodos. Durante esta época perdura la misma estructura territorial y política y al mismo tiempo los órganos de la administración romana continúan desarrollando las funciones de gobierno, con cierta intervención de los monarcas visigodos. Con Eurico, el primer monarca visigodo, y su hijo Alarico se da un paso más al ocupar éstos el lugar que antes había desempeñado el emperador, ejerciendo sus poderes y facultades. A partir de este momento es cuando podemos hablar propiamente de una legislación visigoda; entre otros, puede verse: ARANGio RuIz, Historia del derecho romano, 4. ${ }^{\text {a }}$ ed., trad. esp. (Madrid, 1989), 448 ss. García Moreno, L. A., Historia de la España Visigoda (Madrid, 1989), 317 ss. LALINDE ABADIA, El derecho en la historia de la humanidad (Barcelona, 1982), 38 ss. Finalmente, hemos de decir que son los visigodos uno de los pueblos germánicos más romanizados de los que se asientan en el antiguo territorio del Imperio romano occidental. Entre los autores modernos no deja de reconocerse la profunda romanización de los reyes visigodos; sobre el particular, ver entre otros, D'ORs, «El Código de Eurico», 9.

${ }^{88}$ Como he señalado ya, (cf. la nota 4) las leyes a las que nos vamos a referir tienen su base en la edición de Zeumer en los MGH. Como es sabido, ante la inexistencia de una edición crítica que tuviera en cuenta los fragmentos o manuscritos no manejados por Zeumer, la edición del estudioso alemán es aún de referencia obligada. La Lex Visigothorum, conocida también con los nombres de Liber Iudicum o Liber Iudiciorum, es un libro destinado a la práctica forense y consiste en una recopilación de las leyes promulgadas por los monarcas visigodos que lleva a cabo Recesvinto en el año 654. Las leyes del Liber en la forma recesvindiana que ha llegado hasta nosotros - aunque no todas, pues hay alguna excepción - van precedidas de una de las siguientes inscripciones: Antiqua, Flavius Recaredus Rex, Flavius Sisebutus Rex, Flavius Chindasvintus Rex, Flavius Gloriosus Recesvindus Rex. De forma que, por un lado, recoge leyes cuyos autores aparecen mencionados; y de otro, leyes que estaban recogidas ya en libros. Las leyes que proceden de recopilaciones llevan la rúbrica antiqua; si los redactores las corrigieron, las colocaron bajo la rúbrica de 
Además, en otras sedes de la ley, precisamente, en los títulos primeros de los libros sexto (cf. LV 6,1, de accusationibus criminum) y séptimo (cf. LV 7,1, de indicibus furti) se contienen reglas especiales relativas al enjuiciamiento por delitos ${ }^{91}$. De esta forma y concretamente, sobre la finalización del litigio, disponemos de la información que suministra una ley de Chindasvinto en la LV 2,1,2592, donde esta cuestión se enfoca desde el punto de vista documental.

antiqua enmendata. Un resumen de la historia de la legislación visigótica de Eurico a Witiza puede verse en ZEUMER, Historia de la legislación visigótica, tr. esp. por Carlos ClaVERÍA (Barcelona, 1944), 64 ss. UREÑA y SMENJAUd, La legislación gótico-hispana (Leges Antiquiores-Liber iudiciorum). Estudio crítico (Madrid, 1905), 45 ss. También IGLESIA FERREIRós, La creación del Derecho. Una historia de la formación de un derecho estatal español (Barcelona, 1992). Puede verse en el citado autor un estudio del proceso de formación de la legislación visigoda.

89 Es innegable que «se trata de un código para la práctica forense», cf. ZEUMER, K., Historia de la legislación, 87; «el Liber recoge el derecho creado por la actividad legislativa de unos reyes que son especialmente jueces y está dirigido a autoridades diversas que encuentran en el término iudex y en la correspondiente asunción de tareas judiciales la categoría común donde se engloban», cf. PETIT, C., «De Negotiis Causarum I», en ADHE (1985), 156, aludiendo precisamente a la disposición de Recesvinto contenida en la LV 2,1,27 y cuya rúbrica es la siguiente: Quod omnis, qui potestatem accipit iudicandi, iudicis nomine conseatur ex lege.

90 PetiT, C., «De Negotiis Causarum I», en AHDE, (1985) y «De Negotiis Causarum II», en $A H D E$, (1986), expone el régimen jurídico del proceso visigodo en sus líneas y trámites generales.

91 Podríamos preguntarnos al igual que lo hace PETIT, «De Negotiis causarum I», en $A H D E$, (1985), 160, si el derecho visigodo conoció la distinción entre proceso penal y proceso civil, para responder que «el derecho del Liber se sitúa, una vez más, en el marco evolutivo de la tradición jurídica romana, donde la difusión de la extraordinaria cognitio ya en época clásica fue borrando las diferencias entre los viejos iudicia publica y iudicia privata, de manera que los tiempos y textos postclásicos conocieron un cauce procesal único, aunque compatible con especialidades en función de los intereses en juego», ibidem.

92 La ley de Chindasvinto en LV 2,1,25, bajo la rúbrica: Iudex, qualiter faciat iudicatum, establece lo siguiente: Si de facultatibus vel de rebus maximis aut etiam dignis negotium agitetur, iudex, presentibus utrisque partibus, duo iudicia de re discussa conscribat, que simili textu et suscriptione roborata litigantium partes accipiant. Certe si de rebus modicis mota fuerit actio, sole condiciones, ad quas iuratur, aput eum qui victor extiterit pro ordine iudicii habeantur. De quibus tamen condicionibus et ille, qui victus est, ab eisdem testibus roboratum exemplar habebit. Quod si pars, que pro negotio quocumque conpellitur, professa fuerit aput iudicem, non esse necessarium a petitore dari probationem, quamlibet parve rei sit actio, conscribendum est a iudice suaque manu iudicium roborandum, ne fortasse quelibet ad futurum ex hoc intentio moveatur. Si vero, hordinante iudice, una pars testes adduxerit, et dum oportuerit eorum testimonium debere recipi, pars altera de iudicio se absque iudicis consultum subtraxerit, liceat iudici prolatos testes accipere, et quod ipsi testimonio suo firmaverint, illi. Qui eos protulit, sua instantia consignare. Nam ei, qui fraudulenter se de iudicio sustulit, producere testem alium omnino erit inlicitum; qui scilicet hoc sibi tantum noverit esse concessum, ut antequam testes illi, qui testimonium dede- 
Las causas terminaban normalmente por la sentencia del juez, iudicium, que debía recogerse por escrito presentibus utrisque partibus, dice la ley y ser entregada a cada uno de los litigantes suscrita por aquél; si el pleito comportaba una cuantía escasa, era suficiente con las conditiones iuramenti que documentaban el testimonio recibido como prueba. Además, el pleito se podía zanjar cuando el acusado admitía la reclamación, de manera que en este supuesto la professio era redactada y firmada por el juez, sustituyendo al iudiciun o a las conditiones iuramenti. Si se produce el abandono del juicio por uno de los contendientes en el trámite probatorio, ello no impide practicar las pruebas aportadas por las del otro y dictar sentencia, no obstante el ausente conservaba la posibilidad de tachar a los testigos del otro antes que fallecieran. En términos muy parecidos en cuanto a los aspectos principales de la citada disposición, se manifiesta la ley que se recoge en el Fuero Juzgo, en este caso, en FJ 2,1,23, bajo la siguiente rúbrica: Del iudez cuemo debe iutgar.

Por otra parte, en este apartado de cuestiones previas a tener en cuenta, pueden destacarse algunas leyes que nos ilustran sobre ciertos aspectos generales relacionados con la práctica de la justicia oficial visigoda. Así, por ejemplo, leyes que se refieren a los días festivos en los que no procede la actividad judicial (cf. la disposición de Chindasvinto en LV 2,1,12); horario de trabajo del juez (cf. LV 2,1,20, se trata asimismo de una disposición del citado monarca); en otra ley se recogen reglas de competencia (así por ejemplo, cf. LV 2,1,18); auditores o asesores del juzgador (LV 2,2,2, también de Chindasvinto). La consideración de las citadas leyes, así como de otras, ofrecen elementos para apreciar el elevado grado en que el legislador pretendía regular y ejercer la administración de justicia en términos exclusivos ${ }^{93}$.

\subsubsection{LA RESPONSABILIDAD DEL JUEZ}

«El proceso visigodo, en línea con el derecho tardoantiguo, asume el carácter de método racional de búsqueda de la verdad» ${ }^{94}$. Como se

rant, moriantur, si habuerit fuerit evidenter quod rationabiliterin eis accuset, patienter audiatur a iudice; et si accusatus testis fuerit evidenter convictus, eius testimonium pro nihil habeatur. Unde et si duo testes non remanserit, qui digni in eodem testimonio maneant, ille, qui primum testem obtulerat, infra trium mensium spatium testes alios, qui ceptum negotium firment, inquirere non desistat. Quod si invenire nequiverit, rem universam ille reciiat, qui eam ante visus fuerat possedisse. Iudex sane de omnibus causis, que iudicaverit, exemplar penes se pro conpescendis controversiis reservare curabit.

93 Cf. PetrT, C., «De negotiis causarum II», 64.

94 Vid. PETIT, C., «De negotiis causarum II», 85. 
desprende de las disposiciones visigodas, el juez, al igual que el rey mismo cuando juzga, interviene activamente en el desarrollo de la controversia. Concretamente, ante él se presenta la acusación o demanda; convoca al demandado; en ocasiones, bien por delaciones o de oficio iniciaba los procesos en casos especialmente graves ${ }^{95}$. Además, «en el cuadro general de la Administración de Justicia destaca una falta de unidad y jerarquía, exponente de aquella disgregación reiteradamente señalada como típica del mundo medieval. No hay una, sino múltiples jurisdicciones nacidas por diversas causas. Frente a la jurisdicción ordinaria, centrada mediata o inmediata en la persona del rey, se forman las jurisdicciones exentas de tipo señorial, la eclesiástica, más tarde la mercantil...» ${ }^{96}$

Por lo que respecta a la responsabilidad del juez, la disposición contenida en la LV 2,1,21, antiqua ${ }^{97}$, tiene relación precisamente con el juez que dicta sentencia injusta y distingue claramente entre la sentencia dictada por venalidad del juez - per quodlibet commodum-, y la dictada por simple ignorancia - per ignorantiam, ignoranter- demostrada por el juramento expiatorio del juez.

En los dos supuestos se establece la nulidad de la decisión judicial y además, el castigo en el supuesto del juez venal, de un alium tantum de suo, establece la ley, de la suma en litigio a pagar por el juez al litigante afectado, con la alternativa de reducción a servidumbre a su favor de no poder satisfacer la composición ${ }^{98}$. En la edición ervigiana de la citada ley, se atenuaron las penas anteriores al sustituir la entrega en servidumbre por cincuenta azotes ${ }^{99}$.

95 Ibidem.

96 Vid. FonT Ríus, J. M., Instituciones medievales españolas (Madrid, 1949), 65.

97 LV 2,1,21, antiqua: Si iudex aut per commodum aut per ignorantiam iudicet causam.- Iudex si per quodlibet commodum male iudicaverit et cuicumque iniuste quidquam auferri preceperit, ille, qui a iudice ordinatus ad tollendum fuerat destinatus, ea, que tulit, restituat. Nam ipse iudex contrarius equitatis aliut tantum de suo, quanum auferri iusserat, mox reformet, id est, ablate rei simpla redintegratone concessa, pro satisfactione sue temeritatis aliut tantum, quantum auferri preceperat, de sua facultate illi, quem iniuste damnaverat, reddat. Quod si non habuerit, unde conponat, cum his, que habere dinoscitur, ipse iudex illi, cui conponere debuit, subiaceat serviturus. Si autem per ignorantiam iniuste iudicaverit et sacramentis se potuerit excusare, quod non per amicitiam vel cupiditate aut per commodum quolibet, sed tantumdem ignoranter hoc fecerit: quod iudicabit non valeat, et ipse iudex non inplicetur in culpa.

98 Es la sanción en la edición recesvindiana de la ley antiqua citada.

99 En la edición de Ervigio se establece: Quod si tantum quantum abstulit, non habuerit unde conponat, saltim vel id ipsum ex toto, quod habere videtur, illi, quem damnaverat, pro omni conpositionem restituat. Quod si ex omnibus nihil rerum habuerit, unde conpositionem exsolvat, L publice extensus flagella suscipiat. 
La disposición antiqua citada, claramente perteneciente al Código de Eurico ${ }^{100}$, se encuentra en el Libro 2 - de negotiis causarum- ${ }^{101}$. El cotejo con la legislación bávara ${ }^{102}$, concretamente las disposiciones contenidas en LB $2,17^{103}$ y $18^{104}$ es demostrativo de su pertenencia al $\mathrm{CE}^{105}$ ya que la legislación bávara es tenida en cuenta por Zeumer para la reconstrucción de la legislación de Eurico; considera el autor que la citada legislación había tenido el Código de Eurico como modelo y que presentaba en ocasiones una versión del mencionado Código más auténtica que la procedente de las leges antiquae ${ }^{106}$.

Las dos disposiciones citadas tienen relación con la responsabilidad del juez como consecuencia de su no adecuada actuación. En primer lugar, si el juez actúa por error, el texto de LV 2,1,21, establece concretamente: per ignorantiam; en la LB 2,18, se establece: per errorem, la

100 Cf. D’Ors, A., «El Código de Eurico», en Estudios visigóticos II, (Roma-Madrid, 1960), 57 y asimismo, Zeumer, K., Historia de la legislación visigoda, 160, consideran que la citada antiqua debió de existir ya en el Código de Eurico y ello lo demuestra la coincidencia de la ley con el texto de la Lex Baiuvariorum, cf. LB 2,16,17. Asimismo UREÑA, La legislación gótico-hispana, 351, considera que la citada disposición tiene procedencia euriciana.

101 Según D’Ors, A., «El Código de Eurico», 56, la base euriciana de los cinco títulos, de los que consta el libro 2, es muy reducida. Y continúa diciendo que «los aspectos procesales ocupan poco la atención del legislador euriciano; en esto hay una notable diferencia respecto a Leovigildo, que pormenoriza frecuentemente los trámites procesales».

102 Leges Baiuvariorum, edición de J. Merkel, MGH, LL,3 (Hannover, 1863). Se trata de la legislación bávara que suele datarse hacia la mitad del s. viII.

103 El contenido de LB 2,17 es el siguiente: Iudex si accepta pecunia male iudicaverit, ille qui iniuste aliquid ab eo per sententiam iudicantis abstulerit, ablata restituat. Nam iudex qui perperam iudicaverit, in duplum ei cui damnum intulerit, cogatur exsolvi, quia ferre sententiam contra legum nostrarum statuta praesumpsit. Et in fisco cogatur XL solidos persolvere.

104 LB 2,18: Si vero nec per gratiam nec cupiditatem, sed per errorem iniuste iudicavit, iudicium ipsius in quo errasse cognoscitur, non habeat firmitatem; iudex non vacet ad culpam.

105 El Código de Eurico nos ha llegado de forma fragmentaria. En parte, a través del Palimpsesto Parisino (Lat. 12161) y, además, a través de ciertas leyes que pasaron como antiquae del Código de Leovigildo a la Lex Visigothorum. Cabe destacar, asimismo, como fuente de conocimiento indirecto, otros textos legales como la Lex Baiuvariorum y, en menor medida, la Lex Burgundionum y la Lex Salica. La doctrina, mayoritariamente, ha venido atribuyendo el Código a Eurico. El citado texto legal fue publicado según ZEUMER, Historia de la legislación, 67, después del año 469, pero antes del 481, alrededor del año 475. En adelante, CE. Un estudio de conjunto acerca del CE puede verse en D'Ors, A., «El Código de Eurico», 3 ss. Se utiliza fundamentalmente el CE en la edición de A. D’Ors.

106 Sobre estas leges antiquae, cf. la nota 88. Para la relación de la LV 2,1,21, con las correspondientes del derecho bávaro, esto es: LB 2,17 y 18, cf. ZEUMER, Historia de la legislación, 160-162; precisando los puntos de vista de Zeumer, D’ORS, «El Código de Eurico», 5759. Sobre el particular, ver: UREÑA, La legislación gótico-hispana (Leges Antiquiores-Liber Iudiciorum). Estudio crítico. (Madrid, 1905). En cuanto a la relación entre CE y LB, puede verse un resumen en OSABA, El adulterio uxorio en la Lex Visigothorum (Madrid, 1997), 351. 
parte beneficiada debe restituir, pero el juez no sufre pena alguna, según las citadas disposiciones.

Hay que destacar, asimismo, que las dos leyes mencionadas tienen en común, la exigencia de la restitución de lo injustamente percibido por el litigante vencedor en el juicio (así, se establece en LB 2,17: ille qui iniuste aliquid ab eo per sententiam iudicantis abstulerit, ablata restituat; por otra parte, la LV 2,1,21, dispone que: ille, qui a iudice ordinatus ad tollendum fuerat destinatus, ea que tulit, restituat); hay diferencias, sin embargo, en la regulación contenida en las disposiciones relativas al caso de venalidad del juez. Concretamente, el juez venal sufre por ello una pena por su delito, ahora bien mientras que la LB 2,17, se refiere al duplum del dinero cobrado por el juez ${ }^{107}$, más el pago de 40 solidi para el fisco ${ }^{108}$, en cambio, la disposición citada de la LV, alude al aliut tantum de los daños ocasionados.

Del mismo modo si comparamos la sanción que establece la disposición antiqua a la que nos estamos refiriendo, esto es: el alium tantum de lo arrebatado injustamente, con lo que establecen otras fuentes, citadas infra, se observa también una diferencia importante: concretamente, en el texto del Edicto de Teodorico (Eth 2), y asimismo en los Fragmentos Gaudenzianos ${ }^{109}$, concretamente en FG $10^{110}$, se establece la obligación de pagar el quadruplum. Además, en el citado texto de los Fragmentos Gaudencianos al mantener la pena del quadruplum, cita expresamente al $\mathrm{CE}^{111}$. Por otra parte, hay que destacar asimismo que la entrega en servidumbre del culpable para el supuesto de insolvencia, (atenuada esta pena en la edición de Ervigio, como se ha visto supra), no se encuentra en la LB, pero según D'Ors ${ }^{112}$, podría hallarse ya en el Código de Eurico.

Indicamos finalmente que la disposición antiqua, cuyos aspectos más relevantes acabamos de mencionar, (en LV 2,1,21), se recoge en el FJ 2,1,19, bajo la rúbrica: Del iuez que iuzga tuerto por ruego, ó por

107 Cf. la nota 103.

108 El beneficio del Fisco, tanto en LB como en FG, parece ser un eco del antiguo régimen de confiscación de los bienes que vemos en las Pauli Sententiae.

109 Por lo que respecta a la fecha, la determinación de la misma resulta insegura, cf. García Gallo, A., «Consideración crítica de los estudios sobre la legislación y la costumbre visigodas», en AHDE, 44 (1974), 382.

110 GF 10 establece la pena del quadruplum, a favor del Fisco, no del perjudicado.

111 Ello le lleva a decir a D’Ors, A., «El Código de Eurico», 61 que le parece lo más probable que en el Código de Eurico la pena del juez venal era también la del quadruplum de la pecunia accepta, además de la restitución del daño por el vencedor y no del duplum del daño, como suponía Zeumer.

112 «El Código de Eurico», 61. 
ignorancia $^{113}$. La versión de la citada ley en el Fuero Juzgo, contempla asimismo los dos supuestos a los que hace mención la Lex Visigothorum. 1) El supuesto del juez que da sentencia por venalidad: establece, entre otras cosas: é el iuex por que iudgó contra verdad, peche otro tanto de lo suyo; 2) El supuesto del juez que da sentencia por ignorancia: si el iuez iudgó tuerto por ignorancia ... lo que iudgó non debe valer, y el iuez non debe aver ninguna pena.

Como anteriormente se ha dicho, otras disposiciones de la Lex Visigothorum relativas a la conducta irregular de los jueces se encuentran recogidas en sedes diferentes de las anteriormente mencionadas. De manera que hacemos alusión a otros testimonios de las leyes de algunos monarcas visigodos; concretamente, una disposición de Chindasvinto recogida en LV $6,4,3^{114}$ en la que establece que el obispo y el $d u x$ quedarán encargados de reprimir al juez negligente, se trata de un iudex, amicitia corruptus vel premio ${ }^{115}$. También una disposición de Recesvinto, en LV 7,4,6, de damno iudicis criminosum indebite absolventis tiene relación con las actuaciones de los jueces que a veces actuaban pro patrocinio aut amicitia alicuius, según establece la mencionada ley recesvindiana.

Unos años más tarde, algunas otras leyes advierten a los jueces contra su posible parcialidad en sus actuaciones; cf. por ejemplo, la disposición de Ervigio contenida en la LV 12,3,25 ${ }^{116}$ en relación con el cumplimiento de la legislación antijudaica y, también, la LV 9,1,21117, disposición de Egica que establece que se ha de sancionar a los jueces que no hagan justicia tratándose de los siervos fugitivos. De este modo, adquiere sentido la observación que hace Chindasvinto a los jueces, en

113 FJ 2,1,19. - El Rey Don Flavio Rescindo.-Del iuez que iuzga tuerto por ruego, ó por ignorancia.-El iuez si iudga tuerto por algun ruego, ó por mandar toller aluna cosa á algun omne con tuerto, aquel que levó la cosa por mandado del iuez, entréguela: é el iuez por que iudgó contra verdad, peche otro tanto de lo suyo sin entrega daquela cosa que levó, que debe entregar, é si non oviere otro tanto, cuemo mandó levar, que non pueda facer emienda, si al que non peche todo quanto oviere por emienda. E si ninguna cosa non oviere onde pueda fazer emienda, recuba L. azotes paladinamientre. E si el iuez iudgó tuerto por ignorancia que lo non entendie, si se podier salvar por su iuramiento, que non iudgó tuerto por amor, ni por cobdicia, ni por ruego, si non por ignorancia, lo que iudgó non debe valer, y el iuez, non debe aver ninguna pena.

${ }_{114}$ LV 6,4,3, en la rúbrica de la citada disposición se establece: De reddendo talione et conpositionis summam pro non reddendo talione.

115 Comienza la mencionada ley diciendo: Quod si iudex, amicitia corruptus vel premio, iuxta estimationem rei liberare neclexerit neque continuo ulciscendam iustiterit, iudiciaria protinus potestate privatus, ab epicopo vel duce districtus illi...

116 LV 12,3,25, establece: Ne iudices quicquam de perfidorum excessibus extra sacerdotum conibentiam iudicare presumant.

117 LV 9,1,21: De mancipiis fugitivis et de susceptione fugitivorum. 
su disposición contenida en LV 12,1,1118, para que procedan objetivamente, investigando siempre la verdad y mediante el examen de todas las causas absque personarum acceptione..., según establece la mencionada disposición.

\subsubsection{ORGANO COMPETENTE PARA PEDIR RESPONSABILIDAD AL JUEZ}

Otro aspecto a tener en cuenta tiene relación con la apelación, esto es, quién o qué órgano era competente para exigir responsabilidades al juez y por qué cauce podían dirigir sus quejas las víctimas de la injusticia y que no se recogen en la disposición antiqua, citada supra (nos referimos a la LV 2,1,21). La apelación tiene una regulación defectuosa en la ley de los visigodos ${ }^{119}$, cabe pensar en la competencia de los jueces superiores, comites y duces y, por supuesto, en la competencia del rey; además, en la intervención episcopal, prevista en los concilios de los siglos VI y VII para la vigilancia y control de los gobernantes ${ }^{120}, \mathrm{y}$ así aceptada en las leyes ${ }^{121}$.

Sobre este aspecto de la apelación, podemos mencionar una disposición de Chindasvinto contenida en LV 2,1,24 ${ }^{122}$ la cual se refiere a un tipo de apelación a iudice suspecto en la que intervenía la jerarquía de la Iglesia. Se trata del supuesto en el que temiendo algún litigante la parcialidad del juez secular: si cuiuscumque honoris aut ordinis iudex dicatur haberi suspectus, — según la rúbrica de la citada diposición-,

118 LV 12,1,1, bajo la siguiente rúbrica: De conmonitione principis, qua iubetur, ut iudicium temperent iudices. La citada disposición en la versión del Fuero Juzgo, concretamente en FJ 12,1,1, establece: Cuemo el rey manda á sus jueces que sean mesurados en dar el iuicio.

119 Cf. Petit, C., «De negotiis causarum II», 141-142.

120 Concilio de Toledo III, año 589, en el c. 18: reserva a la jerarquía eclesiástica la inspección del comportamiento de los jueces, para que avisándoles les corrijan o den cuenta al rey de los abusos de aquéllos; asimismo en el Concilio de Toledo IV, año 633, en el c. 32 presenta a los obispos como varones a los que Dios ha encargado la protección del pueblo por lo que deberán amonestar a los jueces opresores de los débies, denunciándolos llegado el caso ante el rey. Y si algún obispo descuidare esto, sea reo delante del concilio. Se cita por la ed. preparada por José Vives, Concilios visigóticos e hispano-romanos. (Barcelona-Madrid, 1963).

121 Cf. la disposición de Recaredo, en LV 12,1,2, cuya rúbrica establece: Ut nullius ex his, qui populorum accipiunt potestatem et curam, quoscumque de opulis aut in sumtibus aut indictionibus inquitare pertemtet.

122 LV 2,1,24, Chindasvinto. Si cuiuscumque honoris aut ordinis iudex dicatur haberi suspectus. - Si quis iudicem aut comitem aut vicarium comitis seu thiuphadum suspectos habere se dixerit et ad suum ducem aditum accedebdi proposcerit aut fortasse eundem ducem suspectum habere dixerit, non sub hac ocassione petitor ac presertim pauper quilibet petiatur ultra dilatione. Sed ipsi, qui iudicant eius negotium, unde suspecti dicuntur haberi, cum episcopo civitatis ad liquidum discutiant adque pertractent et de quo indicaverint pariter conscribant suscribantque iudicium... 
en tal supuesto el juez sospechoso deberá tratar la cuestión juntamente con el obispo, concretamente se refiere la ley, al episcopus civitatis para conocer la causa y dictar un fallo en común. Estableciendo asimismo la mencionada ley que dicho fallo puede ser apelado ante el rey por parte de quien hubiese recusado al juez como sospechoso.

En términos parecidos se manifiesta la disposición contenida en el Fuero Juzgo, concretamente en FJ 2,1,22 que lleva la siguiente rúbrica: Del iuez que a sospecha alguna de las partes. En la disposición citada, (al igual que la contenida en LV 2,1,24), si como consecuencia de la apelación se considera fundada la reclamación, el juez y el obispo son sancionados con la pena establecida para los supuestos de sentencia injusta; por el contrario, si la apelación no está justificada, en ese caso, el apelante es sancionado con idéntica pena. En caso de insolvencia será sancionado con cien azotes (et si non habuerit, unde conpositionem exolvat, $C$ flagellis extensus publice in eiusdem iudicis presentiam verberetur) en presencia del juez (según establecen las dos disposiciones).

Finalmente, es digna de ser destacada una ley de Recesvinto ${ }^{123}$, recogida en LV 2,1,28124, contra la prohibición de pactos de no atacar fallos (injustos), que los jueces en ocasiones obligaban a llevar a cabo.

En definitiva, considera Petit ${ }^{125}$, en relación con esta materia de la apelación, que se ha intentado sin demasiado éxito, reconstruir una escala jerárquica de órganos judiciales a propósito de las previsiones de estas normas, olvidando la naturaleza casuística del Liber Iudiciorum; sigue diciendo el citado autor que «lo único seguro que sabemos se reduce al decisivo papel del obispo como juez del rey con importancia creciente desde la atribución - legal - de tales competencias a fines del siglo vi; si en un principio la colaboración episcopal con la justicia real era prestada más bien en el seno del concilio, desde el reinado de Chindasvinto el obispo local aparece revestido de las funciones concretas de juez de apelación, entre otras cosas» ${ }^{126}$; pone énfasis, además, en destacar que el recurso real a los obispos era «para frenar las desviaciones de los jueces en relación con el derecho oficial» ${ }^{27}$.

123 La disposición de Recesvinto dentro de la línea de revisión de la política de su padre.

124 LV 2,1,28, Recesvinto. Ut omne vinculum, quod post datum iniustum iudicium a causidicis fuerit exactum, habeatur invalidum.- Además de la prohibición a la que se refiere la disposición aludida, puede verse la disposición de Egica acerca de las covenientiae que son condenadas en la la LV 2,2,10, bajo la rúbrica: De his, qui negotia sua iure principali iudicialiter incipiunt et postea inter se citra iudicium pacificare presumunt et ad convenientiam redire.

125 «De negotiis causarum II», 145.

126 Petit, C. De negotiis causarum, II» 146.

127 Ibidem. 


\subsection{Capítulos Gaudenzianos ${ }^{128}$}

El texto legal citado es otra de las fuentes visigodas conocidas; se trata de catorce capítulos, conocidos como Capítulos o Fragmentos Gaudenzianos o de Holkham, cuya publicación inicial tuvo lugar en $1886^{129}$. Por lo que respecta a nuestro tema, esto es el juez que sentencia de forma injusta, concretamente en FG $10^{130}$ se mantiene la pena del quadruplum, pero no ya a favor del perjudicado, sino del Fisco; añadiendo además la indignidad para ser juez. El citado capítulo hace referencia a un edictum que, según D’Ors ${ }^{131}$, no puede ser otro que el Código de Eurico.

\subsection{Edicto de Teodorico ${ }^{132}$}

En relación con el citado texto legal considera García Gallo ${ }^{133}$ que «desde 1955, fecha del primer estudio de Vismara sobre este texto - hasta dos años antes aceptado unánimemente como el más característico del Derecho ostrogodo-, se hace indispensable tomarlo en consideración al tratar de las fuentes visigodas» y esta es la razón por la que incluimos el texto en cuestión dentro del apartado: regulación en el Derecho visigodo.

128 Se cita por la ed. de Zeumer en Monumenta Germaniae Historica (Leges), vol. I (Hannover-Leipzig, 1902), 469-472.

129 Sobre el particular, puede verse, GARCía GALlO, «Consideración crítica de los estudios sobre la legislación y la costumbre visigodas», en AHDE, 44 (1974), 351 y 382-3.

${ }^{130}$ En FG 10, se establece lo siguiente: Si quis iudex voluntate sua iudicaverit, et edictum transgressus fuerit propter pecuniam et aliquem preiudicaverit, quadruplum, quantum acceperit, inferat fisco; et amplius iudex non sit. Quod si causam ipsam non preiudicaverit voluntarie, satis reducatur secundum edicti seriem.

131 «El Código de Eurico», en Estudios Visigóticos II, 60 La sentencia injusta es una transgresión del edictum y, en caso de buena fe del juez, procede la restitución; se dice, secundum edicti seriem, lo que apunta al capítulo de CE correspondiente a LB 2,18, cf. D'ORs, ibidem.

132 Ed. FIRA, Auctores (Florentiae, 1940).

133 Cf. García Gallo, A., «Consideración crítica de los estudios sobre la legislación y la costumbre visigodas», 390. RASI, P., «Sulla paternitá del c.d. Edictum Theodorici regis», en Archivio Giuridico, 145 (1953), 105 ss., ha tratado de demostrar que el Edictum Theodorici regis no pudo ser obra del rey ostrogodo Teodorico el Grande. Por otra parte, VISMARA, G., «El Edictum Theodorici», en Estudios visigóticos I, (Roma-Madrid, 1956), 49-89, lo ha identificado con las leyes de Teodorico II, rey de los visigodos. En definitiva, nos encontramos con un texto de carácter legal, posterior al 458, cuyo lugar de redacción y autor no aparecen suficientemente documentados; si se acepta como buena la atribución a un rey Teodorico, en esas fechas de mediados del siglo v no podría ser otro que el II de los visigodos; si se retrasa a principios del siglo VI, podrían serlo el rey de los ostrogodos o el de los francos, cf. GARCía GALLO, A., «Consideración crítica de los estudios sobre la legislación y la costumbre visigodas», 395. 
En el Edictum llamado de Teodorico ${ }^{134}$ se contempla asimismo las actuaciones dolosas del juez que sentenciaba injustamente. Concretamente, en ETh I-4 ${ }^{135}$ se refiere a nuestro supuesto delictivo; en primer lugar, en ETh1, se distingue la condena adversum caput innocens, en cuyo caso, perdura la equiparación al homicidio (capite puniatur, establece el Edictum), de otros supuestos de daño patrimonial, en todos los cuales el delito se equipara a la rapina, y la pena es del cuadruplum. Por otra parte, en el supuesto concreto contenido en ETh 2: Iudex si pecuniam contra statum aut fortunas cuiuslibet ut sententiam proferret acceperit, la condena en este supuesto es del quadruplum del dinero que venalitatis studio accepit según se establece en el texto del edicto.

\section{Otros testimonios relativos a la conducta de los jueces en la época visigoda}

En este apartado vamos a hacer mención precisamente a algunos testimonios de la obra isidoriana, donde en muchos de los pasajes de sus escritos se evocan las parcialidades, sobornos, etc. de los jueces. Concretamente la parte correspondiente a los jueces en Sentencias ${ }^{136}$, «una de las más vinculadas a la realidad», en opinión de Diesner ${ }^{137}$, presentan un modelo ideal de juez influido por las imágenes de la Biblia, mas informan también del peligro de juzgar a las personas amicitae favore, sive inimicitiarum odio... cf. Isidoro, Sent. 3,53,1 y 3,54,7; otros párra-

134 Se trata de un texto jurídico de extensión media - un prólogo, 154 capítulos y un epílogo-, sin división en libros o títulos, que presenta la materia sin un orden determinado, cf. la ed. FIRA. (Florentiae, 1940).

135 Eth1: Priore itaque loco statuimus, ut si iudex acceperit pecuniam, quatenus aduersum caput innocens contra leges et iuris publici cauta iudicaret, capite puniatur. 2. Iudex si pecuniam contra statum aut fortunas cuiuslibet ut sententiam proferret, acceperit et ex hac re sub iusta fuerit examinatione conuictus, in quadruplum quod uenalitatis studio accepit, exsoluat, illi profuturum contra quem redemptus docebitur tulisse sententiam. 3. Iudex quod immerito prouincialibus rapuerit, amissa dignitate qua male usus est, in quadruplum reddat his duntaxat, quibus immerito constat ablatum: et si defunctus fuerit, ab eius heredibus haec poena poscatur. 4. Officium cuiuslibet iudicii, quod quid ultra quam iussum est exegerit, in quadruplum sub fustuaria poena cogatur exsoluere iis, quibus inclite monstrabuntur ablata.

136 En Santos padres españoles, II. Introducciones, versión y notas de: Julio CAMPOS RuIZ e Ismael Roca MELIÁ en BAC (Madrid, 1971).

137 DiESNER, Hans-Joachim, considera que el grado de feudalización de la sociedad hispanovisigoda impondría que un juez joven o de bajo rango contara con el patrocinio de algún poderoso, a veces del rey, por lo que las posibilidades de juzgar libremente debían ser excepcionales, cf Isidor von Sevilla und das westgotische Spanien, (Berlin, 1977), 56 ss. del mismo autor: Isidor von Sevilla und seiner Zeit (Sttutgart, 1973) y asimismo, "Zeitsgeschichte und Gegenwartsbezug bei Isidor von Sevilla», en Philologus, 119 (1975), 92-97. 
fos aluden asimismo al peligro de corrupción judicial por regalos de los poderosos (cf Sent. 3,54,4-5) ${ }^{138}$; además, de la perversión del juicio: $t i$ more, cupiditate, odio et amore, según se dice en Sent. 3,54,7.

Asimismo, en Synonima ${ }^{139}$, 1,6 ss., presenta Isidoro el alma torturada que se queja de ser un desamparado carente de protector y defensa, uno de los ingenuos que no siendo patrono ni cliente se encuentra aislado y expuesto a los ataques de los bandos que dividen a los pueblos, acusado de crímenes que ignoraba por falsos testigos y crueles jueces que en su contra sentencian; inocente, ha de sufrir condenas a muerte o a destierro...: hay una evocación a las parcialidades cometidas por unos jueces envueltos en vínculos de patrocinio y de esta forma los que padecen sus actuaciones sufren los efectos de la amicitia, del timor o del metus potestatis sobre los encargados de la justicia.

\section{Gastos del proceso}

Finalmente, en relación con este punto, hay que destacar que algunas disposiciones de la ley de los visigodos hacen alusión a la citada materia: así, concretamente, una disposición de Chindasvinto sobre tortura servil, en LV 6,1,5 ${ }^{140}$. Asimismo, la edición de Ervigio a la disposición contenida en la LV 2,1,26, que bajo la rúbrica: De commodis atque damnis iudicis vel saionis ${ }^{141}$, se refiere precisamente al supuesto particular de la partición de la herencia ${ }^{142}$.

138 Entre otras cosas, se establece: ...plus enim obtinet mentem censoris amor lucri uam aequitas iudicii.

139 Synonima sive de lamentatione animae peccatricis, ed. J. P. Migne, PL, 83, cols. 825-868.

${ }^{140}$ LV 6,1,5, Chindasvinto: «... Si autem dolo servum alienum quispiam subdendum questioni intenderit, et dominus servi, qui accusatur, per probationem eum potuerit de obiecto crimine reddere innocentem, accusator eius alium paris meriti servum accusati domino cogatur exolvere, et dispendium, quod dominus eius in adprobationem innocentis servi pertulerit, prou rationabiliter iudex reddi perpenderit, ab iniusto accusatore exactum domino servi restituatur. Acerca de la citada ley, como dice Petiт, C., «De Negotiis Causarum II», 139, habrá que discernir si se trata de una simple reparación del daño causado o bien, propiamente, de un gasto procesal.

${ }^{141}$ En la disposición mencionada, edición de Ervigio se establece, entre otras cosas: Cognovimus multos iudices eo, quod, per cupiditatis occasionem supergredientes legum ordinem, ex causis tertiam sibi presumant tollere partem...

142 A esta temática se refiere LALinde AbADiA, J., «Los gastos del proceso en el derecho visigodo», en Studi in onore di E. Volterra, vol. V (Milano, 1971), 99-120. 
